\title{
TITLE:
}

\section{Characteristics of stemflow for tall stewartia (Stewartia monadelpha) growing on a hillslope}

\author{
$\operatorname{AUTHOR}(\mathrm{S}):$ \\ Liang, Wei-Li; Kosugi, Ken'ichirou; Mizuyama, \\ Takahisa
}

\section{CITATION:}

Liang, Wei-Li ... [et al]. Characteristics of stemflow for tall stewartia (Stewartia monadelpha) growing on a hillslope. Journal of Hydrology 2009, 378(1-2): 168-178

\section{ISSUE DATE:}

2009-11

URL:

http://hdl.handle.net/2433/87312

\section{RIGHT:}

c 2009 Elsevier B.V. All rights reserved.; This is not the published version. Please cite only the published version.; この論文は出版社版でありませ ん。引用の際には出版社版をご確認ご利用ください。 
1 Characteristics of stemflow for tall stewartia (Stewartia monadelpha) growing on a hillslope

3 Wei-Li LIANG *, Ken'ichirou KOSUGI, and Takahisa MIZUYAMA

4

5 Department of Forest Science, Graduate School of Agriculture, Kyoto University, Kyoto, Japan.

6

$7 \quad *$ Corresponding author

$8 \quad$ E-mail addresses: weili.liang7@gmail.com ; iritu@kais.kyoto-u.ac.jp

9

10 Tel.: +81-75-753-6091; fax: $+81-75-753-6088$

11 Lab. of Erosion Control, Dep. of Forest Science, Graduate School of Agriculture, Kyoto Univ.,

12 Kitashirakawa, Oiwake-Cho, Sakyo-Ku, Kyoto, 606-8502, Japan. 


\section{Summary}

3 The characteristics of stemflow were observed in a tall stewartia (Stewartia monadelpha) deciduous forest on

4 a hillslope in central Japan, revealing new findings for a previously unreported type of deciduous forest.

5 Using 2-year observations of 250 rainfall events, we analyzed seasonal and spatial variations in stemflow for

6 several trees, and applied additional data sets of throughfall and plant area index (PAI) to produce a rough

7 estimate of seasonal variations in rainfall redistribution processes and canopy architecture for a single tree.

8 Compared to previous findings for other deciduous tree species, the ratios of throughfall, stemflow, and

9 interception to open-area rainfall obviously varied with PAI changes for tall stewartia. Meteorological

conditions of rainfall amount, rainfall intensity, wind speed, and wind direction had little effect on stemflow

11 generation, which was mainly affected by variation in canopy architecture. Three novel characteristics of

12 stemflow were identified for several tall stewartia trees. First, the yearly stemflow ratio at the forest-stand level for tall stewartia (12\%) was high compared to previous findings on beech and oak stands, indicating tall stewartia has considerably high potential to generate a great amount of stemflow. Second, stemflow tended to 
1 Keywords Deciduous broad-leaved tree; Forested hillslope hydrology; Rainfall partitioning;

2 Spatiotemporal variations

\section{Introduction}

In rainfall redistribution processes in forest stands, a part of rainfall is intercepted by the canopy, while other

parts are partitioned into throughfall and stemflow through the canopy as diffuse and point inputs to the

forest floor, respectively. Therefore, the rainwater amount reaching the forest floor is considerably heterogeneous. Many studies have examined the effects of rainfall redistribution processes on soil water dynamics (e.g., Voigt, 1960; Durocher, 1990; Bouten et al., 1992; Keim et al., 2006; Liang et al., 2007). Most of these studies emphasized that the spatial distribution of throughfall mainly affects soil water dynamics. The low ratios of stemflow were usually disregarded, and interception was usually dealt with as the difference between gross and net rainfall (the sum of throughfall and stemflow). Throughfall reaching the forest floor either falls from foliage as foliage drip or passes directly through gaps within the canopy as direct throughfall; these types of throughfall are mainly determined by the canopy architecture. Thus, previous studies reported various spatial distributions of throughfall. For example, higher throughfall was observed at the canopy perimeter in a Norway spruce (Picea abies [L.] Karst.) forest (Beier et al., 1993), at a middle position within the canopy of a black spruce (P. mariana [Mill.] Britton, Sterns \& Poggenburg) forest

19 (Carleton and Kavanagh, 1990), and near the tree stems in a Sitka spruce (P. sitchensis [Bong.] Carr.) forest

20 (Ford and Deans, 1978), indicating large interspecies variations in spatial throughfall distribution, even 
1 within the same genus.

Although spatial variation in throughfall contributes to spatial variation in soil water, throughfall patterns may not necessarily be reflected in the soil moisture patterns (Pressland, 1976; Raat et al., 2002).

Excluding spatial variability of soil thickness and physical properties, one explanation would be the influence of localized concentrations of stemflow input (Voigt, 1960; Keim et al., 2006). Although previous studies paid little attention to the effects of stemflow due to the low ratio of stemflow to precipitation reported in many forest stands (e.g., Bouten et al., 1992; Keim et al., 2006; Belk et al., 2007), the point input characteristic of stemflow may have major implications for soil water dynamics, even for tree species with a

9 low ratio of stemflow to precipitation. Aboal et al. (1999) quantified the stemflow of 30 sample trees belonging to six different species in a laurel forest and found that precipitation could be concentrated up to

1112.8 times in the infiltration areas of the trees by stemflow, even though the annual stemflow only represented $6.85 \%$ of the gross precipitation. Durocher (1990) recorded very rapid water movement beneath trees and suggested that this movement was caused by small-scale spatial variability in the water input to the

14 soil surface by stemflow. In our previous study (Liang et al., 2007), we conducted detailed observations of soil water dynamics around a tree for many storm events, and observed that maximal soil water storage was more than 100 to $200 \%$ of the cumulative open-area rainfall at the points downslope from a tree stem on a

17 hillslope; we attributed this to concentrated stemflow rapidly flowing into soil layers along the pathways around roots as bypass flow. Therefore, the stemflow infiltration process, differing from the throughfall

19 infiltration process, has great implications for observations and simulations of soil water dynamics (Liang et al., 2009). 
In addition to studies on soil water dynamics, research has focused on the relationship between global leafless conditions. Although some studies have reported that throughfall and stemflow increased, and

changes in climate and rainfall redistribution processes, which are expected to greatly and directly impact ecosystems. Under the climatic conditions found in Japan, the predicted change in forest stands from coniferous trees to broad-leaved evergreen trees, due to natural thinning but also to global warming, would cause significant changes in water movement and groundwater recharge processes (Tanaka et al., 2008). Iida et al. (2005) observed that during the period of forest stand succession from Japanese red pine to oak trees, there was a substantial increase in stemflow, essentially no change in throughfall, and a substantial decrease in interception. Therefore, clarifying the characteristics of stemflow in broad-leaved forests is important in light of the lack of previous research and potential succession from coniferous to broad-leaved forests in Japan caused by accelerating global climate change.

Except for the factors of forest types and locations, stemflow yield is greatly influenced by meteorological conditions such as rainfall amount, rainfall intensity, wind speed, and wind direction (Crockford and Richardson, 2000; Levia and Frost, 2003). Although Levia and Frost (2003) pointed out general tendencies of stemflow yield, which increased with the magnitude of a precipitation event and wind speed but decreased with rainfall intensity of incident gross precipitation, they also presented some study cases that contrasted with generally held assumptions, exemplifying the diverse relationship between stemflow yield and meteorological conditions. Moreover, characteristics of stemflow in deciduous forests should vary more than in other forest types because of changes in canopy architecture between leafed and interception decreased, in the leafless period of deciduous forest stands (Helvey and Patric, 1965; Neal et al., 
1 1993; Staelens et al., 2008), those studies mostly focused on beech or oak species; few studies have

2 examined other deciduous tree species (Llorens and Domingo, 2007). Thus, stemflow studies conducted in

3 beech or oak forests may be insufficient to represent the characteristics of stemflow in all deciduous forests.

The purpose of this study was to clarify the characteristics of stemflow in a type of deciduous forest

6 long-term observations of many rainfall events, we quantitatively analyzed the seasonal and spatial

7 variations in stemflow for several trees. We also collected additional throughfall data to provide a rough

8 estimate of seasonal variations in the ratios of stemflow, throughfall, and interception to open-area rainfall

9 for a single tree. We compared the results observed in tall stewartia with previously reported findings for

10 other tree species.

\section{Methods and materials}

\subsection{Study area}

Observations were conducted on a hillslope at the Kamigamo Experimental Station of Kyoto University (Fig. 
1 only a few centimeters of snow for a short time in winter.

The hillslope had a mean gradient of $28^{\circ}$, with brown forest soil classified as Cambisol underlain by

sandstone and slate. It was predominantly covered with tall stewartia (Stewartia monadelpha), planted in

1956 and surrounded by a mixed conifer-broad-leaved forest. The genus Stewartia includes 21 species that

are distributed throughout Japan, Korea, China, and eastern America (Li et al., 2002). Of these, tall stewartia

is widespread in natural forests in western and southern parts of Japan, classified in the US Department of

Agriculture (USDA) hardiness zones of 6B through 8B. Like most species of Stewartia, tall stewartia is a deciduous broad-leaved tree with upward-tilting branches (Fig. 2a) and smooth-exfoliated bark (Fig. 2b). Tall stewartia exhibited leaf fall in November and regrowth in April in the study area. We separated canopy architecture into leafed and leafless periods based on field observations of the foliage states.

\subsection{Observations of stemflow, throughfall, and canopy architecture for a single tree}

To provide a rough estimate of the ratios of stemflow, throughfall, and interception to open-area rainfall for tall stewartia growing on a hillslope, observations were conducted for a single tall stewartia, tree S2 (Fig. 1b) during the observation period from July 2006 through August 2007. 
To estimate the amount of throughfall under the canopy of tree S2, we installed a tipping-bucket rain

gauge (Davis, 7852M; $0.2 \mathrm{~mm}$ per tip; water collection area, $200 \mathrm{~cm}^{2}$ ) at each of five points (TF-5p): $100 \mathrm{~cm}$ and $50 \mathrm{~cm}$ upslope from the tree stem, and $50 \mathrm{~cm}, 100 \mathrm{~cm}$, and $200 \mathrm{~cm}$ downslope from the stem of tree S2 (Fig. 1c) during the observation period from July 2006 through April 2007. The canopy area of tree S2 was divided into three parts: annuli of 0-75 $\mathrm{cm}$ (canopy area 1: $\left.1.74 \mathrm{~m}^{2}\right), 75-150 \mathrm{~cm}$ (canopy area 2: $4.31 \mathrm{~m}^{2}$ ), and farther (canopy area 3: $9.73 \mathrm{~m}^{2}$ ) from the stem (Fig. 1c). Thus, rainwater collected by tipping-bucket gauges at $50 \mathrm{~cm}, 100 \mathrm{~cm}$, and $200 \mathrm{~cm}$ from the stem were presumed to represent throughfall amounts within canopy area 1, canopy area 2, and canopy area 3 , respectively. Then, the average throughfall amount within the canopy of tree S2 could be estimated as an area-weighted mean for all measurement points. To increase the resolution of throughfall measurement, we additionally installed the same type of tipping-bucket rain gauge at each of three points (total was eight, TF- 8 p): $50 \mathrm{~cm}, 100 \mathrm{~cm}$, and $200 \mathrm{~cm}$ laterally from the stem of tree S2 (Fig. 1c) during the observation period from May 2007 through June 2008. The relationship between TF- $5 p$ and TF- $8 p$ during this observation period was used to estimate TF- $8 p$ during the former observation period during which only TF-5p was measured. Although the sample size of throughfall was small in comparison to previously published studies (Staelens et al., 2006; Zimmermann et al., 2007), throughfall in our study was an additional data set that helped to provide a rough estimate of rainfall redistribution processes relating to seasonal changes in stemflow.

To estimate seasonal variations in canopy architecture, the plant area index (PAI) was measured monthly above TF-5p with an optical plant canopy analyzer (LI-COR, Inc., LAI-2000) using default parameters and calibration from 7 May 2006 through 21 April 2007. We used a $90^{\circ}$ mask on the lens of the 
1 analyzer and conducted four measurements to estimate PAI over all azimuth angles at each point and to

2 avoid contamination of the measurement by the instrument operator. Open-sky calibration measurement was

3 conducted at an open site $200 \mathrm{~m}$ from the observation slope before PAI measurement at each point. Although

4 the absolute value of PAI was influenced by the hillslope and adjacent coniferous forests for some azimuth

5 angles, the average PAI for all measurement points could roughly represent the seasonal variations in canopy

6 architecture in the study area. This measurement method for PAI has well applied in previous studies (Aboal

et al., 2000; Deguchi et al., 2006; Kosugi et al., 2007).

\subsection{Observations of stemflow for several trees}

To verify general trends in stemflow generation, we selected four other tall stewartia trees (S3, S4, S5, and

S6 in Fig. 1b) to measure stemflow during the observation period from June 2007 through June 2008. SF-up and SF-down were also separately collected for these trees. We used four 16-L containers with siphon drainage equipment to determine SF-down based on water-level changes in the containers (previously calibrated in the laboratory) and tipping-bucket gauges (Davis, 7852M) to measure SF-up. In our previous study (Liang et al., 2007), we conducted detailed observations of soil water dynamics around tree S1 (Fig. 1b). From 1 April through 30 June 2008 (i.e., the leafed period only), we additionally measured SF-up and SF-down of tree S1 using the same method as described above for tree S2. 
1 Technology, Inc., 200LR) to estimate the canopy projection area for each tree in both leafed and leafless

2 periods (Fig. 1b). The same impulse was used to measure tree height, calculated by the distance and angle

3 from the impulse to the top and base of a tree. The canopy projection area determined during the leafed

4 period was divided into the upslope and downslope sides from the trunk (Table 1); the overlapping areas

5 were divided equally into adjacent canopies for each tree (Fig. 1b and c). The canopy projection areas of

6 observation trees S1-S6 were not overlapped by the mixed conifer-broad-leaved forest (Fig. 1b).

During all observation periods, measurements of stemflow and throughfall were simultaneously and

8 automatically recorded at 5-min intervals by a data logger (Campbell, CR-1000). Gross rainfall (open-area

9 rainfall) data provided by the Kamigamo Experimental Station of Kyoto University was measured using a

10 tipping-bucket rain gauge (Ikeda RH-5; $0.5 \mathrm{~mm}$ per tip, water collection area, $314.16 \mathrm{~cm}^{2}$ ) at an open site

$11112 \mathrm{~m}$ from the observation slope. Wind speed and wind direction data were provided by the Japan

12 Meteorological Agency; these data were measured at a station approximately $6.6 \mathrm{~km}$ from the observation

13 slope.

\subsection{Data analysis}

17 Meteorological data of open-area rainfall and wind were analyzed for each rainfall event. An individual consecutive hours without rain. To provide a rough estimate of rainfall redistribution processes, we 
1 leafed and leafless periods. Stemflow was determined by the sum of SF-up and SF-down per canopy

2 projection area of tree $\mathrm{S} 2$, and interception was estimated as open-area rainfall minus the sum of throughfall

3 and stemflow for each rainfall event.

To clarify how changes in canopy architecture affect rainfall redistribution processes, monthly average

5 PAI values were compared to the monthly ratios of total throughfall, stemflow, and interception amounts to

6 open-area rainfall for tree S2. We compared the results to those of three previous studies (Deguchi et al.,

7 2006; Sraj et al., 2008; Staelens et al., 2008) that reported seasonal PAI changes and the ratios of throughfall,

8 stemflow, and interception amount to gross precipitation in deciduous forests. As in our study, the three

9 previous studies estimated interception as gross precipitation minus the sum of throughfall and stemflow.

To estimate stemflow yield on the forest-stand level for tall stewartia, we calculated the ratio of total

11 stemflow volume per total canopy projection area of trees S1-S6 to open-area rainfall. We compared results

12 to values reported in previous studies for beech (Giacomin and Trucchi, 1992; Chang and Matzner, 2000;

Santa Regina and Tarazona, 2000; Mosello et al., 2002) and oak (Moreno et al., 2001; Silva and Rodriguez,

$$
\begin{array}{r}
S f_{\text {up }}^{\text {supply }}=\left(S f_{\text {up }}^{\text {yield }}+S f_{\text {down }}^{\text {yield }}\right) \times C_{\text {up }} /\left(C_{\text {up }}+C_{\text {down }}\right) \\
S f_{\text {down }}^{\text {supply }}=\left(S f_{\text {up }}^{\text {yield }}+S f_{\text {down }}^{\text {yield }}\right) \times C_{\text {down }} /\left(C_{\text {up }}+C_{\text {down }}\right),
\end{array}
$$

20 where $S f_{\text {up }}{ }^{\text {yield }}$ and $S f_{\text {down }}{ }^{\text {yield }}$ correspond to SF-up and SF-down volumes, and $C_{\text {up }}$ and $C_{\text {down }}$ represent upslope 
1 and downslope canopy areas (Table 1), respectively. Then, we compared each of $S f_{\text {up }}^{\text {supply }}$ and $S f_{\text {down }}^{\text {supply }}$ to

$2 S f_{\text {up }}^{\text {yield }}$ and $S f_{\text {down }}$ yield to clarify the spatial variation in stemflow for trees growing on a hillslope.

\section{Results and discussion}

\subsection{Seasonal variation in canopy architecture and open-area rainfall events}

Average PAI for five measurement points was clearly larger in the leafed period than in the leafless period

(Fig. 3). Average PAI values in the leafed and leafless periods were 3.7 and 2.2, respectively, for all measurement points, with a maximum of 4.1 measured in July and a minimum of 2.0 measured in March.

Figure 4a shows meteorological data for open-area rainfall and wind speed measured in the whole

Excluding the failed observation period from 5 to 19 April 2007 (Fig. 4a), 250 rainfall events were observed. in summer, those histograms showed similar frequency distributions in both leafed and leafless periods (Fig. 
1 periods.

3.2 Comparison of how changes in canopy architecture affect seasonal variation in stemflow for tall versus PAI. Figure $5 \mathrm{~b}$ shows the relationships between PAI and variations in rainfall redistribution reported in three previous studies. Study 1 (Sraj et al., 2008) used two data sets measured on the south- and north-facing slopes of a mixed deciduous forest. Throughfall was sampled using two large gutter collectors in combination with ten manual roving gauges; stemflow was measured for single ash and oak trees on each of two plots; PAI values were derived from hemispherical photography. Seasonal variations in rainfall redistribution processes were small; the higher throughfall ratio in the leafed period was attributed to the

The amount of TF-5p and TF-8p differed slightly: TF-8p was 1.16 and 0.96 times TF-5p in the leafed and leafless periods, respectively. We used these relationships to estimate TF-8p when only TF-5p was measured.

We observed significant seasonal variations: throughfall increased and stemflow and interception decreased from the leafed period to the leafless period. The ratios of stemflow, throughfall, and interception to open-area rainfall were 28,50 , and $22 \%$ in the leafed period, and 19,63 , and $18 \%$ in the leafless period, respectively.

Throughfall, stemflow, and interception ratios varied obviously with changes in PAI (Fig. 5a), showing a clear inverse correlation in throughfall versus PAI, and positive correlations in stemflow and interception

西
high intensity of precipitation in summer, and no seasonal variation was found in stemflow on either plot. 
1 Study 2 (Deguchi et al., 2006) sampled throughfall at nine points and measured stemflow for eight species in

2 a multispecies forest predominantly covered with deciduous oak and Japanese clethra trees, whereby PAI

3 values were measured using a plant canopy analyzer (LAI-2000). That study showed that throughfall

4 decreased and interception increased in the leafed period, but there was no seasonal variation in stemflow. In

5 Study 3 (Staelens et al., 2008), throughfall was sampled at 20 points, and stemflow was measured for a single

6 mature deciduous beech tree where PAI had been previously observed by Mussche et al. (2001) using a plant

7 canopy analyzer (LAI-2000). The results showed that throughfall greatly decreased and interception greatly

8 increased in the leafed period, but the stemflow ratio increased by only $3 \%$ from the leafed period to the

9 leafless period.

In contrast to the results of these studies (Fig. 5b), our results indicated that the ratios of throughfall,

11 stemflow, and interception to open-area rainfall greatly varied with changes in PAI values (Fig. 5a),

12 indicating that changes in canopy architecture greatly affected rainfall redistribution processes for tall

13 stewartia. In particular, we identified a clear positive correlation between stemflow and PAI for tall stewartia,

14 which was a contrary trend to previous findings showing a nonobvious or inverse correlation in stemflow

15 versus PAI. In addition to tree S2, greater stemflow in the leafed period was also found on the other tall

16 stewartia trees (Table 2). The ratio of stemflow to open-area rainfall was 1.3-2.0 times greater in the leafed

17 period than in the leafless period for trees S3-S6. This suggests that greater stemflow in the leafed period

18 than in the leafless period was a general trend for tall stewartia.

Previous studies have recognized the tendency of stemflow in deciduous forest stands to be greater in 
1 seasonal meteorological conditions and changes in canopy architecture (Crockford and Richardson, 2000;

2 Levia and Frost, 2003). To clarify the effect of meteorological conditions on stemflow, the ratios of stemflow

3 for S2 were compared to rainfall amount, average rainfall intensity, and average wind speed for rainfall

4 events in the leafed and leafless periods (Fig. 6). With regard to the relationship between stemflow ratios and

5 rainfall amount (Fig. 6a), we found that stemflow ratios significantly increased with the event amount for

6 events $<5 \mathrm{~mm}$, but did not increase significantly for events $\geq 5 \mathrm{~mm}$. It is likely that a greater proportion of a

7 tree stem is saturated with increasing rainfall input, so the area contributing to stemflow increases until a

8 threshold rainfall input that saturates all areas capable of producing stemflow is reached (Carlyle-Moses and

9 Price, 2006). We did not observe a significant tendency with regard to the relationship between stemflow

10 ratios and average rainfall intensity (Fig. 6b). Although Crockford and Richardson (2000) indicated that

11 stemflow production decreased with the intensity of incident gross precipitation because high intensity

12 rainfall may produce branch flow that exceeds flow path capacity (Herwitz, 1987), this tendency was not

13 significant in our study, even for events with an average intensity $>3 \mathrm{~mm} / \mathrm{h}$. We also did not observe a

14 significant relationship between stemflow ratio and average wind speed (Fig. 6c), although Levia and Frost

15 (2003) indicated that a greater area of a tree's surface may be wetted during events with greater wind speeds,

16 thus contributing to stemflow production. This result was likely due to that the events were mild (low wind

17 speed and intensity) in this study compared to those previously found to affect stemflow. Overall, we found

18 no clear influences of rainfall amount, rainfall intensity, or wind speed on the stemflow ratio, whereas our

19 results clearly revealed differences in the stemflow ratio by leafed and leafless periods (Fig. 6). In addition to

20 the result of slight differences in seasonal meteorological conditions (Fig. 4b), we suggest that the 
1 characteristic of greater stemflow in the leafed period for tall stewartia was greatly affected by changes in

2 canopy architecture rather than seasonal meteorological conditions. larger orthogonally projected branch area, which could capture more rainfall (Helvey and Patric, 1965). For example, Giacomin and Trucchi (1992) reported that stemflow in a beech coppice forest was always higher

6 in the leafless period except for the small rainfall class $(1-5 \mathrm{~mm})$; they presumed that foliage prevented the

7 branches from becoming wet and conducting water down the stem in the leafed period. However, rainwater

8 intercepted by leaves would not only be detained on the leaf surface; it could also drip down as throughfall or

9 flow to the stem via branches as stemflow. The increased throughfall ratio of $13 \%$ from the leafed to leafless periods could be considered an effect of leaves on rainfall redistribution processes, contributing 9 and $4 \%$ of

11 rainfall to stemflow and interception in the leafed period, respectively. Therefore, we suggest that leaves

12 have a positive effect on the generation of stemflow for tall stewartia, in which a large part of rainwater intercepted by leaves would flow downward via upward-tilting branches to become stemflow (Fig. 2a); this would lead to greater stemflow in the leafed period than in the leafless period. previous studies. First, rainfall redistribution studies in deciduous forest stands have focused on a few tree species, mostly beech and oak (Llorens and Domingo, 2007); there has thus been little information on processes for other deciduous tree species. Second, as pointed out by Deguchi et al. (2006), most studies of deciduous forests have only included measurements from a single season, not both the leafed and leafless 
1 especially those with a canopy or branch architecture similar to that of tall stewartia.

2

\subsection{Comparison of stemflow amount for tall stewartia and other deciduous tree species}

As shown in Fig. 5, tall stewartia tree S2 showed greater stemflow than other deciduous tree species reported in the three previous studies, suggesting the capability of tall stewartia forests to yield high stemflow. The yearly stemflow ratio at the forest-stand level for tall stewartia (12\%) was high compared to the ratios for beech and oak forest stands in the previous studies (Fig. 7). Even in the leafless period, the smaller stemflow ratio at the forest-stand level for tall stewartia was higher than the means of yearly stemflow ratios for beech (6\%) and oak (5\%). Additionally, Helvey and Patric (1965) reported average stemflow ratios of $4 \%$ in the leafed period and $6 \%$ in the leafless period for deciduous trees in the eastern United States. The ratios reported by Helvey and Patric (1965) were all lower than stemflow ratios in the tall stewartia stand, for which we estimated ratios of $14 \%$ in the leafed period and $8 \%$ in the leafless period (Fig. 7). These results indicate that tall stewartia has considerably high potential to generate a great amount of stemflow compared to other deciduous tree species reported in previous studies.

The large generation of stemflow by tall stewartia is probably attributable to its branch architecture, which is also the main factor affecting intraspecific variability in stemflow production rates (Levia and Frost, 2003). Herwitz (1987) clarified the strong positive relationship between branch flow and branch inclination in a laboratory experiment. In that experiment, branch flow yields were more than $80 \%$ of simulated rainfall when branch inclination angles were greater than $60^{\circ}$ above the horizontal. As shown in Fig. 2a, the branch 
1 inclination angles of the tall stewartia were almost all greater than $60^{\circ}$ above the horizontal and trained to a

2 single trunk, which could have contributed to the generation of stemflow. Moreover, bark characteristics also

3 affect the stemflow amount. In general, smooth bark has lower bark water storage capacity and contributes to

4 the generation of a continuous flow path, which would increase stemflow yield (Levia and Herwitz, 2005).

5 Helvey and Patric (1965) also attributed stemflow being greater in young stands than in old stands to the

6 smoother bark with branches tending to grow upward rather than outward in young stands. Therefore,

7 compared to some beech and oak species that exhibit drooping branches and rougher bark, it is reasonable

8 that tall stewartia with upward-tilting branches (Fig. 2a) and smooth bark (Fig. 2b) generated a greater

9 amount of stemflow than beech and oak. Although bark water storage capacity is an important factor

10 affecting stemflow yield, we did not obtain these data for tall stewartia: bark water storage capacity is

11 difficult to measure in the field and laboratory measurements involve many potential errors (Levia and Herwitz, 2005). Future studies should focus on improving estimation methods of bark water storage capacity in the field.

3.4 Generation of stemflow along the upslope and downslope sides of the tree stems 
1 approximately 19 and 12 times greater than the SF-up volume in the leafed and leafless periods, respectively.

2 This result suggests that the concentration of stemflow to the downslope side of the tree stems, causing an

3 asymmetrical spatial distribution of stemflow, was a general trend for tall stewartia growing on the hillslope.

4 Regarding seasonal variations, SF-down volume was greater in the leafed period than in the leafless period,

5 whereas there were no obvious seasonal variations observed in the SF-up volume for trees S2-S6. The

6 different trends in the seasonal variations of SF-down and SF-up are probably due to the generation of SF-up

7 being small and thus not reflecting much seasonal variation.

There was an obvious seasonal distinction in the relationship between wind direction and spatial

variation in stemflow (Fig. 9), in which SF-down volumes were approximately 90 and 50 times greater than

SF-up volumes in the leafed and leafless periods, respectively; however, we found no clear correlation

between wind direction and the ratio. In particular, the ratio did not increase when the wind came from the east-southeast, which could bring rainfall to the downslope side of the stems. The result indicates that the asymmetrical generation of stemflow (Fig. 8) was not explained by wind-driven rainfall in this study. 
1 and $S f_{\text {down }}^{\text {yield }}$ ) for trees S4 and S5. However, for trees S1, S2, S3, and S6, Sf $f_{\text {down }}^{\text {yield }}$ values were obviously

2 greater than $S f_{\text {down }}{ }^{\text {supply }}$, and $S f_{\text {up }}^{\text {yield }}$ values were obviously smaller than $S f_{\text {up }}^{\text {supply }}$. The difference between

$3 S f_{\text {down }}{ }^{\text {yield }}$ and $S f_{\text {down }}^{\text {supply }}$ (i.e., $S f_{\text {down }}^{\text {yield }}-S f_{\text {down }}^{\text {supply }}$ ) is identical to the difference between $S f_{\text {up }}^{\text {supply }}$ and $S f_{\text {up }}^{\text {yield }}$

4 (i.e., $S f_{\text {up }}{ }^{\text {supply }}-S f_{\text {up }}{ }^{\text {yield }}$ ) and represents the water volume that was supplied by the upslope side of the canopy

5 and turned into the stemflow along the downslope side of the stem. This indicates the water volume

6 transported from the upslope to the downslope sides of the stem. Figure 10 shows the relationship between

$7 S f_{\text {up }}^{\text {supply }}$ and $S f_{\text {up }}^{\text {yield }}$ for trees S1-S6 for each rainfall event. $S f_{\text {up }}{ }^{\text {yield }}$ was approximately $10 \%$ of $S f_{\text {up }}{ }^{\text {supply }}$ for

8 trees S1, S2, and S6, and 50\% of $S f_{\text {up }}^{\text {supply }}$ for S3 and S4. Thus $90 \%$ of the stemflow supplied by the upslope

9 side of the canopy would turn into the stemflow along the downslope side of the trunk for trees S1, S2, and

10 S6. The ratio was $50 \%$ for trees S3 and S4. Therefore, in addition to the uneven area between the upslope

11 and downslope sides of the canopy, asymmetrical stemflow pathways between the upslope and downslope

12 sides of the trunk also contributed to the greater stemflow volume along the downside of the stem. We

13 presumed that the asymmetrical stemflow pathways were caused by the tilt of the tree trunk toward the

14 downslope direction as indicated in Fig. 2a and Table 1. In Fig. 10, tree S5 showed a different trend from the

15 other trees; in tree $\mathrm{S} 5, S f_{\text {up }}{ }^{\text {yield }}$ was ten times greater than $S f_{\text {up }}{ }^{\text {supply }}$. This result was likely due to rainwater

16 falling directly on the upslope side of the trunk. Greater $S f_{\text {up }}^{\text {yield }}$ than $S f_{\text {up }}^{\text {supply }}$ values were also measured at

17 tree S4 for some rainfall events (Fig. 10). Therefore, the effect of asymmetrical stemflow pathways was not

18 obvious for the tree with the small upslope canopy projection area; as a result, the stemflow volume supplied

19 from upslope or downslope sides of the canopy was consistent with the stemflow volume yielded along the

20 upslope or downslope sides of the stem (i.e., trees S4 and S5 in Fig. 8). 
In our previous study (Liang et al., 2007), we found that asymmetrical and local generation of

stemflow caused large and rapid increases in soil water content and frequent generation of a saturated zone at

the soil-bedrock interface in the downslope region but not in the upslope region for tree S1. Such spatial variation in stemflow on a hillslope would not only have great implications for hillslope hydrological processes but also for spatial root development (Ford and Deans, 1977; Herwitz and Levia, 1997) and soil erosion-accelerated downslope trees (Herwitz, 1986). Moreover, these results are important for improving prediction accuracy for rainfall infiltration simulated on a forested hillslope, particularly in determining how to input stemflow into the calculation domain in a spatial model (Liang et al., 2009). Although some previous studies have measured stemflow on forested hillslopes (e.g., Park and Cameron (2008) conducted a study on rolling hills with slopes of up to $48 \%$ ), the asymmetrical generation of stemflow upslope and downslope of tree stems has never been carefully measured. We presume that this asymmetrical generation of stemflow probably occurs in general with trees growing on a hillslope. Therefore, we suggest that future studies conducting observations of stemflow for trees growing on a hillslope should consider the spatial variation in stemflow.

\section{Conclusions}

In this study, we clarified the characteristics of stemflow using long-term observations of many rainfall events for a previously unreported type of deciduous forest (tall stewartia) on a hillslope. Three novel characteristics of stemflow were observed for several tall stewartia trees. 
1 1. Our observations suggested the potential for large amounts of stemflow generation. The yearly stemflow rate at the forest-stand level for tall stewartia (12\%) was high compared to those reported in previous studies for beech and oak forest stands. The high level for tall stewartia is attributed to its upward-tilting branches and smooth bark.

2. Stemflow tends to be greater in the leafed period than in the leafless period, a feature that has not been revealed previously. We suggest that leaves have a positive effect on the generation of stemflow for tall stewartia; a large part of rainwater, once intercepted by the leaves, would flow downward via upward-tilting branches to become stemflow, causing more stemflow in the leafed period than in the leafless period.

3. A greater amount of stemflow was generated on the downslope side of the stem than on the upslope side. enough to represent the amount of stemflow on the upslope and downslope sides of the trunk. The greater stemflow volume along the downside of the trunk was also attributable to asymmetrical stemflow pathways between the upslope and downslope sides of the trunk caused by the tilt of tree trunk toward the downslope direction. We presume that this asymmetrical generation of stemflow probably occurs in general on trees growing on a hillslope and thus has important implications for hillslope hydrological processes. 
1 method (Link et al., 2004) to estimate canopy capacity and the threshold amount of rainfall required before

2 stemflow generated could be one direction for further studies, which would be helpful in understanding the

3 dynamics and mechanisms of rainfall redistribution processes in the forest with high stemflow ratio.

4

5

\section{Acknowledgments}

6 optical plant canopy analyzer (LAI-2000). Helpful suggestions by anonymous reviewers improved the (201830 and 19380087).

\section{References}

15

manuscript. This work was supported by grants from the Monbukagakusho Fund for Scientific Research

Aboal, J.R., Jimenez, M.S., Morales, D. and Gil, P., 2000. Effects of thinning on throughfall in Canary Islands pine forest -- the role of fog. Journal of Hydrology, 238(3-4): 218-230.

Aboal, J.R., Morales, D., Hernandez, M. and Jimenez, M.S., 1999. The measurement and modelling of the variation of stemflow in a laurel forest in Tenerife, Canary Islands. Journal of Hydrology, 221(3-4): $161-175$. 
1 Beier, C., Hansen, K. and Gundersen, P., 1993. Spatial variability of throughfall fluxes in a spruce forest. Environmental Pollution, 81(3): 257-267.

Belk, E.L., Markewitz, D., Rasmussen, T.C., Maklouf Carvalho, E.J., Nepstad, D.C. and Davidson, E.A., 2007. Modeling the effects of throughfall reduction on soil water content in a Brazilian Oxisol under a moist tropical forest. Water Resources Research, 43(8): W08432.

Bouten, W., Heimovaara, T.J. and Tiktak, A., 1992. Spatial patterns of throughfall and soil water dynamics in a Douglas Fir stand. Water Resources Research, 28(12): 3227-3233.

Carleton, T.J. and Kavanagh, T., 1990. Influence of stand age and spatial location on throughfall chemistry Forestiere, 20(12): 1917-1925.

Carlyle-Moses, D.E. and Price, A.G., 2006. Growing-season stemflow production within a deciduous forest of southern Ontario. Hydrological Processes, 20(17): 3651-3663.

Chang, S.C. and Matzner, E., 2000. The effect of beech stemflow on spatial patterns of soil solution chemistry and seepage fluxes in a mixed beech/oak stand. Hydrological Processes, 14(1): 135-144.

Crockford, R.H. and Richardson, D.P., 2000. Partitioning of rainfall into throughfall, stemflow and 2903-2920. interception loss: Application of the revised Gash model. Journal of Hydrology, 318(1-4): 80-102. 
Ford, E.D. and Deans, J.D., 1977. Growth of a Sitka spruce plantation: spatial distribution and seasonal fluctuations of lengths, weights and carbohydrate concentrations of fine roots. Plant and Soil, 47(2): 463-485.

Ford, E.D. and Deans, J.D., 1978. Effects of canopy structure on stemflow, throughfall and interception loss in a young Sitka spruce plantation. Journal of Applied Ecology, 15(3): 905-917.

Giacomin, A. and Trucchi, P., 1992. Rainfall interception in a beech coppice (Acquerino, Italy). Journal of Hydrology, 137(1-4): 141-147.

Helvey, J.D. and Patric, J.H., 1965. Canopy and litter interception of rainfall by hardwoods of eastern United States. Water Resources Research, 1(2): 193-206.

Herwitz, S.R., 1986. Infiltration-excess caused by stemflow in a cyclone-prone tropical rainforest. Earth Surface Processes and Landforms, 11(4): 401-412.

Herwitz, S.R., 1987. Raindrop impact and water flow on the vegetative surfaces of trees and the effects on stemflow and throughfall generation. Earth Surface Processes and Landforms, 12(4): 425-432.

Herwitz, S.R. and Levia, D.F., 1997. Mid-winter stemflow drainage from bigtooth aspen (Populus grandidentata Michx) in Central Massachusetts. Hydrological Processes, 11(2): 169-175.

Holscher, D., Kohler, L., Leuschner, C. and Kappelle, M., 2003. Nutrient fluxes in stemflow and throughfall in three successional stages of an upper montane rain forest in Costa Rica. Journal of Tropical Ecology, 19: 557-565. 
red pine to evergreen oak. Journal of Hydrology, 315(1-4): 154-166.

2 Keim, R.F., Tromp-van Meerveld, H.J. and McDonnell, J.J., 2006. A virtual experiment on the effects of evaporation and intensity smoothing by canopy interception on subsurface stormflow generation. Journal of Hydrology, 327(3-4): 352-364.

Kosugi, Y., Takanashi, S., Tanaka, H., Ohkubo, S., Tani, M., Yano, M. and Katayama, T., 2007. Evapotranspiration over a Japanese cypress forest. I. Eddy covariance fluxes and surface conductance characteristics for 3 years. Journal of Hydrology, 337(3-4): 269-283.

Kyoto Univ., 2007. Meteorological observations in the Kyoto University forests. No. 14, Field Science Education and Research Center Division of Forest Biosphere, Kyoto.

Levia, D.F. and Frost, E.E., 2003. A review and evaluation of stemflow literature in the hydrologic and biogeochemical cycles of forested and agricultural ecosystems. Journal of Hydrology, 274(1-4): $1-29$.

Levia, D.F. and Herwitz, S.R., 2005. Interspecific variation of bark water storage capacity of three deciduous tree species in relation to stemflow yield and solute flux to forest soils. CATENA, 64(1): 117-137.

Li, J.H., Del Tredici, P., Yang, S.X. and Donoghue, M.J., 2002. Phylogenetic relationships and biogeography of Stewartia (Camellioideae, Theaceae) inferred from nuclear ribosomal DNA ITS sequences. Rhodora, 104(918): 117-133.

Liang, W.-L., Kosugi, K. and Mizuyama, T., 2007. Heterogeneous soil water dynamics around a tree growing on a steep hillslope. Vadose Zone Journal, 6(4): 879-889.

Liang, W.-L., Kosugi, K. and Mizuyama, T., 2009. A three-dimensional model of the effect of stemflow on 
soil water dynamics around a tree on a hillslope. Journal of Hydrology, 366(1-4): 62-75.

2 Link, T.E., Unsworth, M. and Marks, D., 2004. The dynamics of rainfall interception by a seasonal temperate rainforest. Agricultural and Forest Meteorology, 124(3-4): 171-191.

Llorens, P. and Domingo, F., 2007. Rainfall partitioning by vegetation under Mediterranean conditions. A review of studies in Europe. Journal of Hydrology, 335(1-2): 37-54.

Moreno, G., Gallardo, J.F. and Bussotti, F., 2001. Canopy modification of atmospheric deposition in oligotrophic Quercus pyrenaica forests of an unpolluted region (central-western Spain). Forest Ecology and Management, 149(1-3): 47-60. Control (CONECOFOR). Journal of Limnology, 61(Suppl. 1): 77-92.

Mussche, S., Samson, R., Nachtergale, L., De Schrijver, A., Lemeur, R. and Lust, N., 2001. A comparison of optical and direct methods for monitoring the seasonal dynamics of leaf area index in deciduous forests. Silva Fennica, 35(4): 373-384.

Neal, C., Robson, A.J., Bhardwaj, C.L., Conway, T., Jeffery, H.A., Neal, M., Ryland, G.P., Smith, C.J. and the effects of storm damage. Journal of Hydrology, 146: 221-233.

Park, A. and Cameron, J.L., 2008. The influence of canopy traits on throughfall and stemflow in five tropical trees growing in a Panamanian plantation. Forest Ecology and Management, 255(5-6): 1915-1925. 
1 Pressland, A.J., 1976. Soil moisture redistribution as affected by throughfall and stemflow in an arid zone shrub community. Australian Journal of Botany, 24(5): 641-649.

Raat, K.J., Draaijers, G.P.J., Schaap, M.G., Tietema, A. and Verstraten, J.M., 2002. Spatial variability of throughfall water and chemistry and forest floor water content in a Douglas fir forest stand. Hydrology and Earth System Sciences, 6(3): 363-374.

Santa Regina, I. and Tarazona, T., 2000. Nutrient return to the soil through litterfall and throughfall under beech and pine stands of Sierra de la Demanda, Spain. Arid Soil Research and Rehabilitation, 14(3): 239-252.

Schweingruber, F.H., 1996. Influence of mass movement. In: F.H. Schweingruber (Editor), Tree rings and environment dendroecology. Haupt Publ., Bern, Switzerland, pp. 271-287.

Silva, I.C. and Rodriguez, H.G., 2001. Interception loss, throughfall and stemflow chemistry in pine and oak forests in northeastern Mexico. Tree Physiology, 21(12-13): 1009-1013.

Sraj, M., Brilly, M. and Mikos, M., 2008. Rainfall interception by two deciduous Mediterranean forests of contrasting stature in Slovenia. Agricultural and Forest Meteorology, 148(1): 121-134.

Staelens, J., De Schrijver, A., Verheyen, K. and Verhoest, N.E.C., 2006. Spatial variability and temporal stability of throughfall water under a dominant beech (Fagus sylvatica L.) tree in relationship to canopy cover. Journal of Hydrology, 330(3-4): 651-662.

Staelens, J., De Schrijver, A., Verheyen, K. and Verhoest, N.E.C., 2008. Rainfall partitioning into throughfall, stemflow, and interception within a single beech (Fagus sylvatica L.) canopy: influence of foliation, rain event characteristics, and meteorology. Hydrological Processes, 22(1): 33-45. 
1 Tanaka, T., Iida, S., Kakubari, J. and Hamada, Y., 2008. Effect of forest stand succession from conifer trees to broad-leaved evergreen trees on infiltration and groundwater recharge processes. In: C.A.e. al. Modelling. IAHS Publ. 321, pp. 54-60.

5 Voigt, G.K., 1960. Distribution of rainfall under forest stands. Forest Science, 6(1): 2-10.

6 Zimmermann, A., Wilcke, W. and Elsenbeer, H., 2007. Spatial and temporal patterns of throughfall quantity and quality in a tropical montane forest in Ecuador. Journal of Hydrology, 343(1-2): 80-96. 


\section{$1 \quad$ Figure and Table captions}

3 Figure 1 (a) Map showing the small catchment area with a small channel (dashed line). (b) Topography of

4 the observation area showing the locations of the tall stewartia tree stems, and tree canopy projection areas in

5 the leafed and leafless periods. (c) Setting points of rain gauges to estimate throughfall within radiuses of

$6 \quad 0-75 \mathrm{~cm}$ (canopy area 1), 75-150 cm (canopy area 2), and farther (canopy area 3) from the stem of tree S2.

7 The observation area shown in Fig. $1 \mathrm{~b}$ was surrounded by a mixed conifer-broad-leaved forest; trees $\mathrm{S} 1$ to

S6 were selected to measure stemflow.

Figure 2 (a) Upward branches and (b) smooth-exfoliated bark of tall stewartia. Trees S2, S4, S5, and S6 in

(a) correspond to those shown in Fig. $1 b$.

Figure 3 Temporal variations in plant area index (PAI) from May 2006 to April 2007. Symbols are average

PAI values for five measurement points (TF-5p), and error bars are standard deviations. The shaded area indicates the leafless period.

Figure 4 (a) Cumulative open-area rainfall for each month, and rainfall amount, average rainfall intensity, and average wind speed for all observation periods. The arrows in Fig. 4a indicate the four observation periods for throughfall measured at five points (TF-5p) and eight points (TF-8p), stemflow measured for a 
1 single tree (S2) and for several trees (S1, S3, S4, S5, and S6), respectively. Shaded areas indicate the leafless

2 periods. Observations failed from 5 to 19 April 2007.

4 Figure 5 Relationship between monthly average plant area index (PAI) and monthly average ratios of throughfall, stemflow, and interception to open-area rainfall (a) in the present study and (b) three previous studies: Study 1 (Sraj et al., 2008), Study 2 (Deguchi et al., 2006), and Study 3 (Staelens et al., 2008, with data from Mussche et al., 2001). There were two data sets from two measurement plots in Study 1.

Figure 6 Relationship of stemflow ratios for tree S2 and (a) rainfall amount, (b) average rainfall intensity, and (c) average wind speed for rainfall events in the leafed and leafless periods.

Figure 7 Stemflow ratios at the forest-stand level and single-tree level (S1-S6) for tall stewartia, and stemflow ratio at the forest-stand level for beech (Giacomin and Trucchi, 1992; Chang and Matzner, 2000; Santa Regina and Tarazona, 2000; Mosello et al., 2002) and oak (Moreno et al., 2001; Silva and Rodriguez, 2001; Mosello et al., 2002; Holscher et al., 2003). The stemflow ratio at the forest-stand level for tall stewartia was calculated as the ratio of total stemflow per total canopy area of trees S1-S6 to open-area rainfall. Stemflow ratios for tall stewartia were separated into leafed, leafless, and yearly periods. Boundaries line marks the mean, and error bars indicate the 10th and 90th percentiles. 
1 Figure 8 Relationship between open-area rainfall and stemflow measured along the upslope (SF-up) and

2 downslope (SF-down) sides of tree stems S1-S6 in the leafed and leafless periods. In each panel, four

3 regression lines were derived from the relationships of each $S f_{\text {up }}^{\text {yield }}, S f_{\text {down }}^{\text {yield }}, S f_{\text {up }}^{\text {supply }}$, and $S f_{\text {down }}^{\text {supply }}$ in Eq.

4 (1) to open-area rainfall, respectively.

6 Figure 9 Relationship between wind direction and the ratio of SF-down to SF-up volumes for tree S2. The arrow indicates the downslope direction of the hillslope (east-southeast) corresponding to that shown in Fig.

$1 b$.

Figure 10 Relationship between $S f_{\text {up }}^{\text {supply }}$ and $S f_{\text {up }}^{\text {yield }}$ for trees $\mathrm{S} 1-\mathrm{S} 6$ for each rainfall event. $S f_{\text {up }}^{\text {supply }}$

11 calculated by Eq. (1) corresponds to the stemflow volume supplied by the upslope canopy, and $S f_{\text {up }}$ yield is the stemflow volume measured on the upslope side of the trunk. The difference between $S f_{\text {up }}^{\text {supply }}$ and $S f_{\text {up }}^{\text {yield }}$ (i.e.,

$13 S f_{\text {up }}^{\text {supply }}-S f_{\text {up }}{ }^{\text {yield }}$ ) represents the water volume that was supplied by the upslope side of the canopy and 14 turned into the stemflow along the downslope side of the trunk.

Table 1 Upslope, downslope, and total canopy projection area, height, diameter at breast height (DBH), and angle of downslope inclination of the study tree stems.

Table 2 The ratio of stemflow to open-area rainfall for trees S1-S6 in the leafed, leafless, and yearly periods. Observation for tree S1 was only conducted in the leafed period. 
Figure 1

(a)

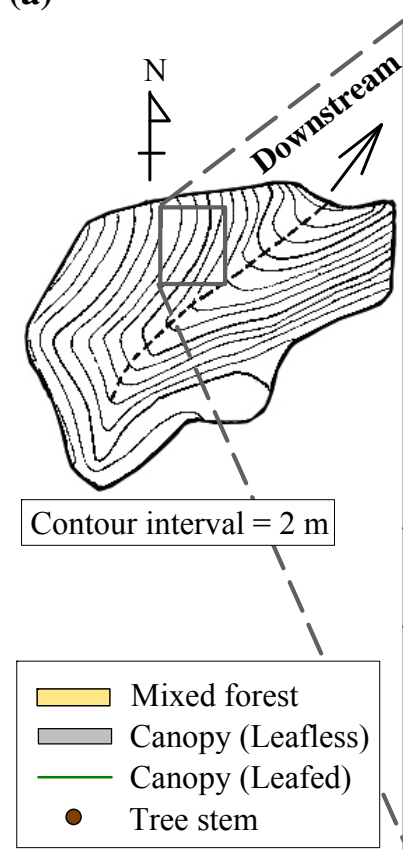

(b)

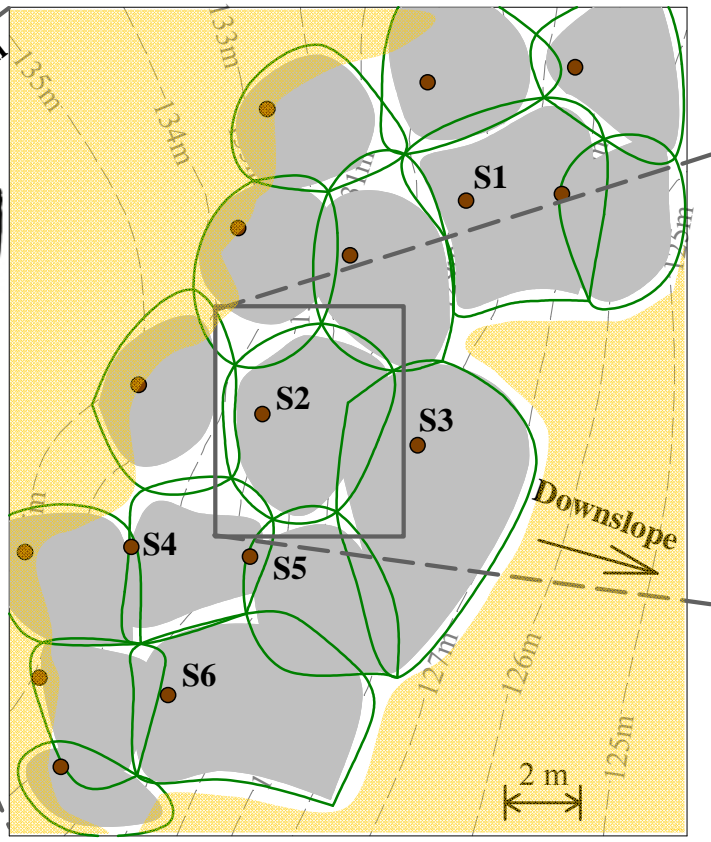

(c)

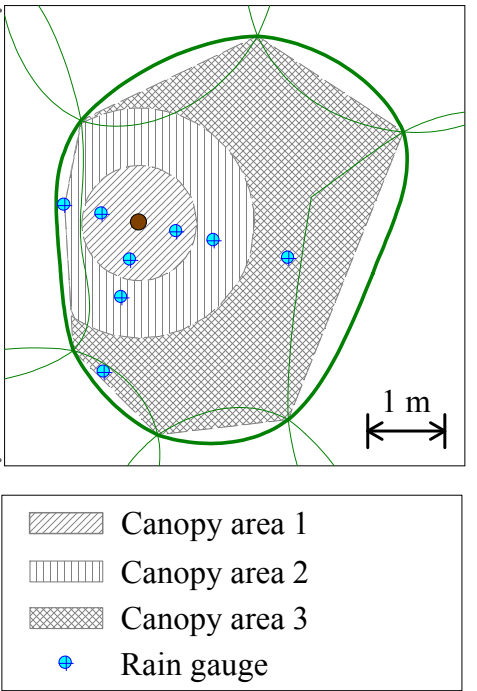


$1 \quad$ Figure 2

(a)

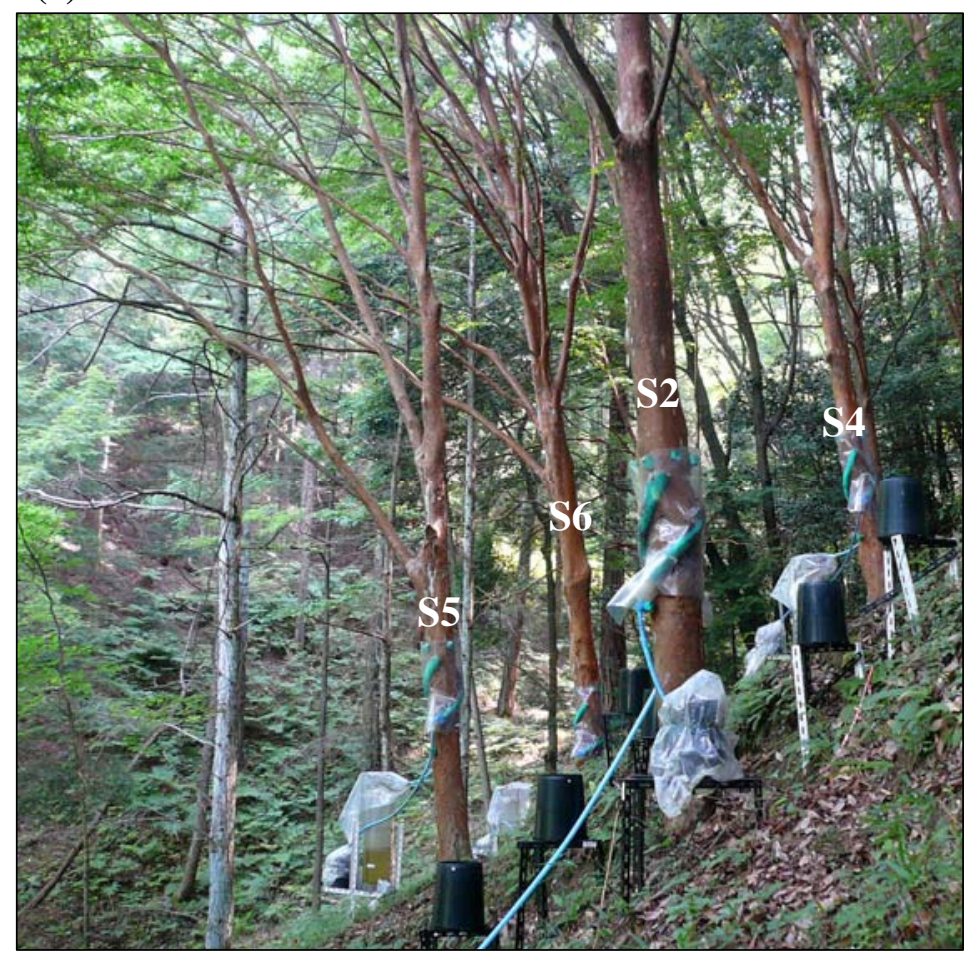

(b)

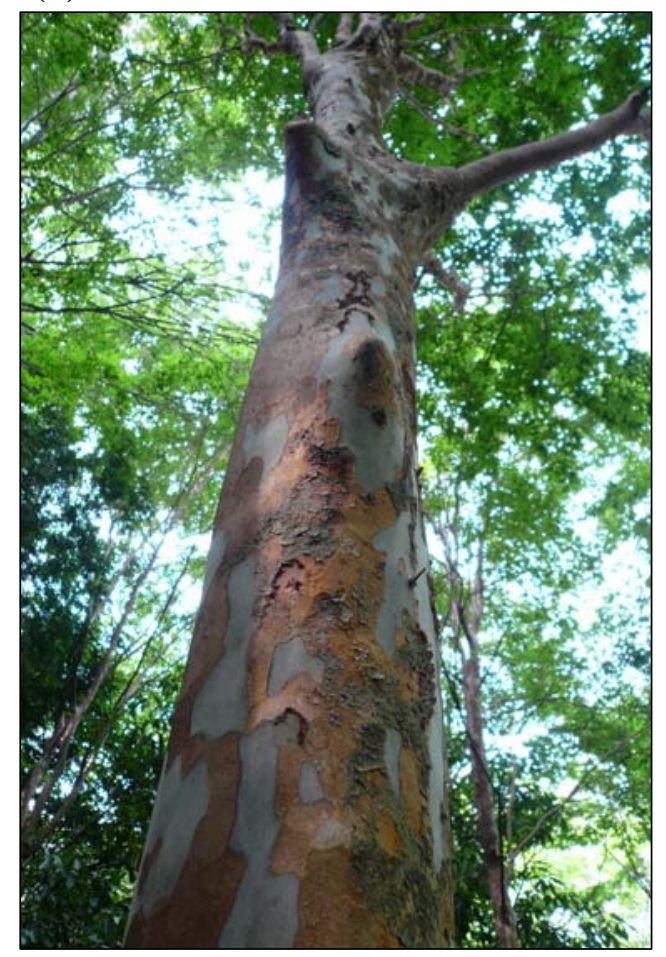


$1 \quad$ Figure 3

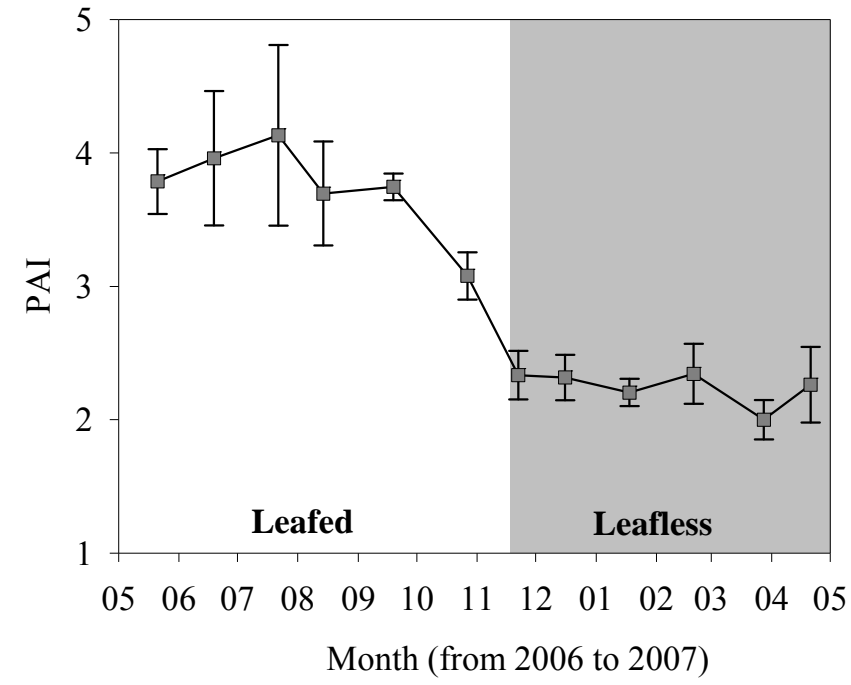


Figure 4

(a)

$\longleftarrow$ Observations of TF-5p for tree S2

Obeservations of stemflow for tree S2

Observations of TF-8p for tree S2 $\rightarrow$

Observations of stemflow for several trees $\longrightarrow$

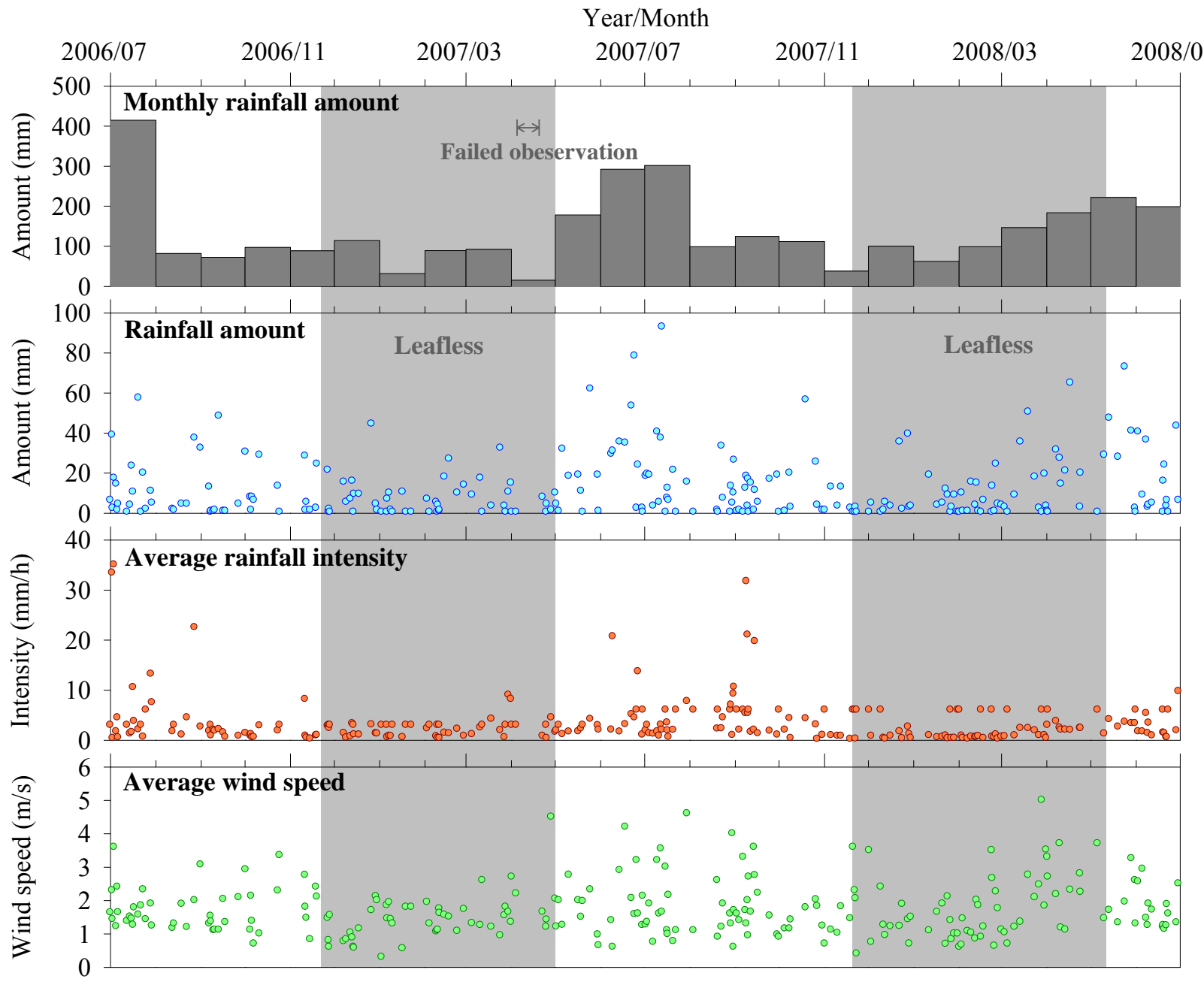

(b)

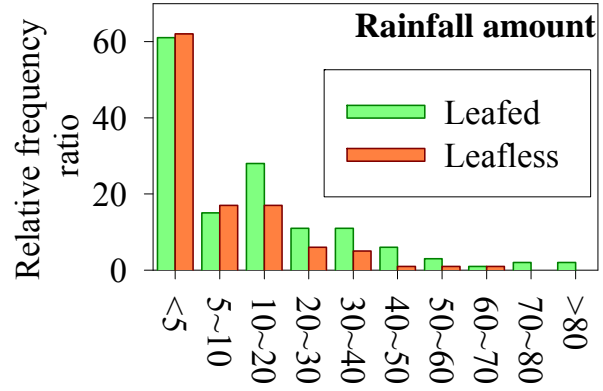

Rainfall amount (mm)

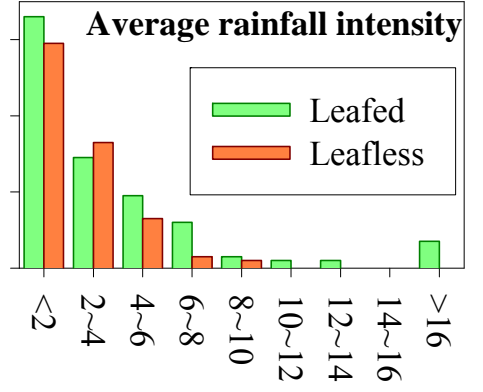

Rainfall intensity $(\mathrm{mm} / \mathrm{h})$

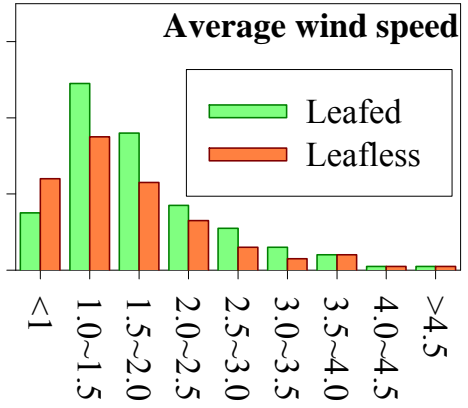

Wind speed $(\mathrm{m} / \mathrm{s})$ 
Figure 5

(a) Present study

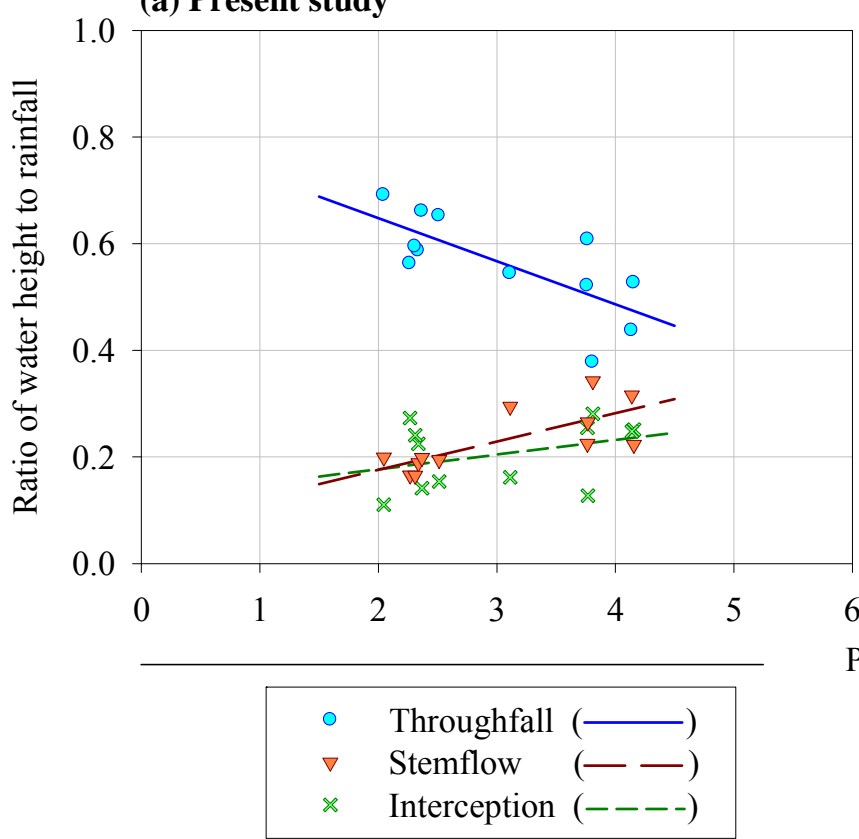

(b) Previous studies

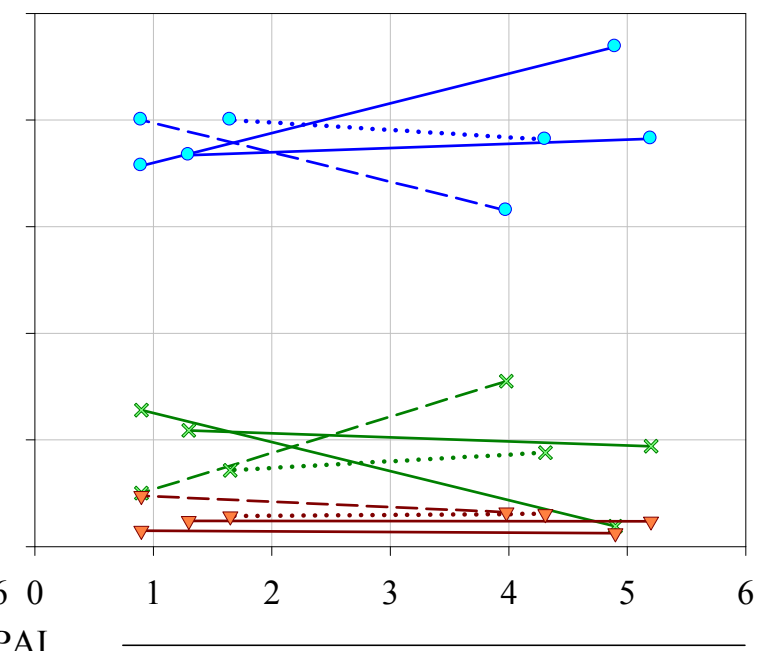

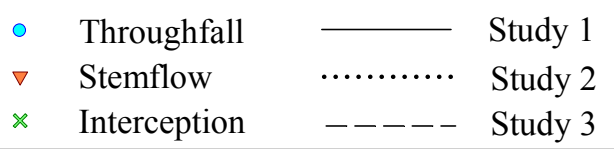


Figure 6

(a) Rainfall amount

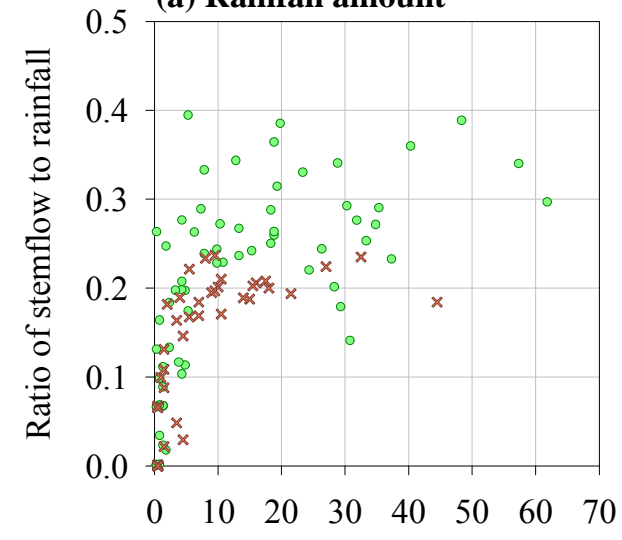

Rainfall amount (mm) (b) Average rainfall intensity

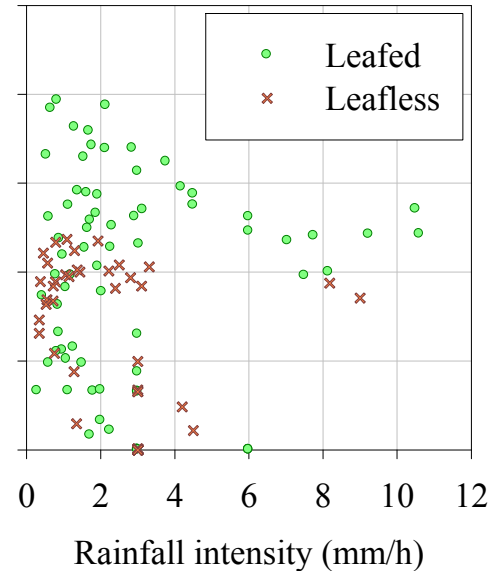

(c) Average wind speed

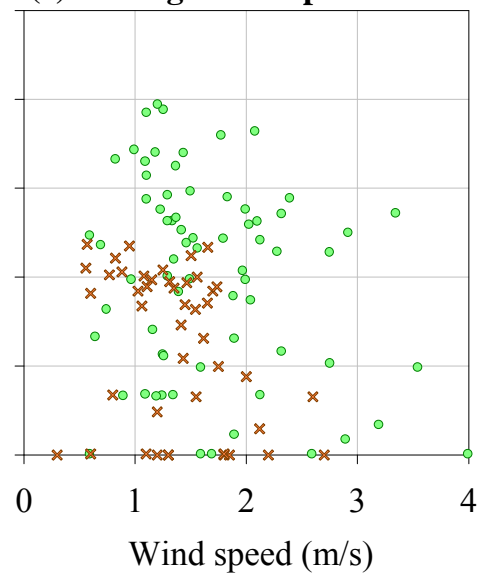


$1 \quad$ Figure 7

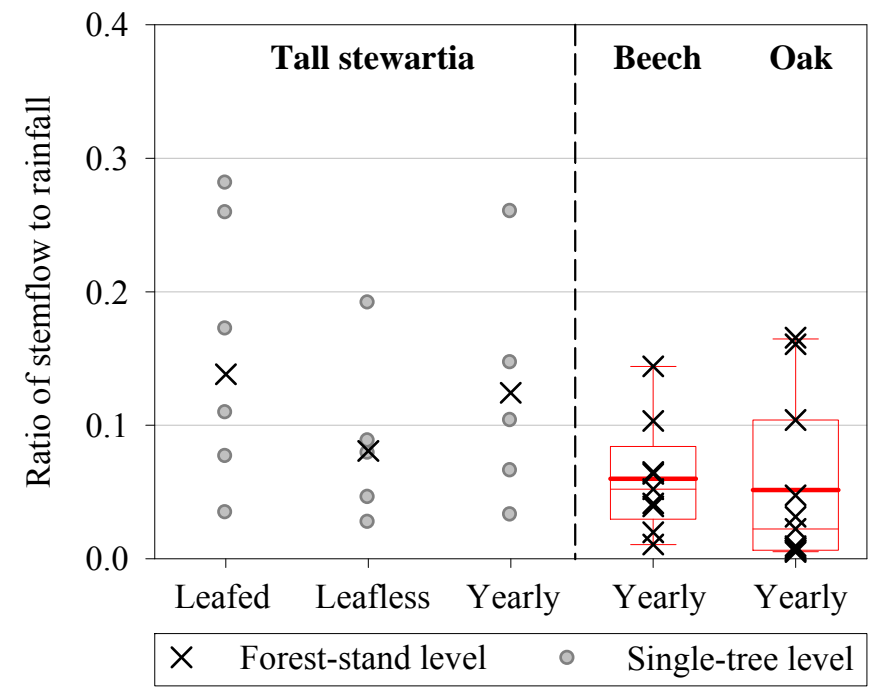

2 
Figure 8
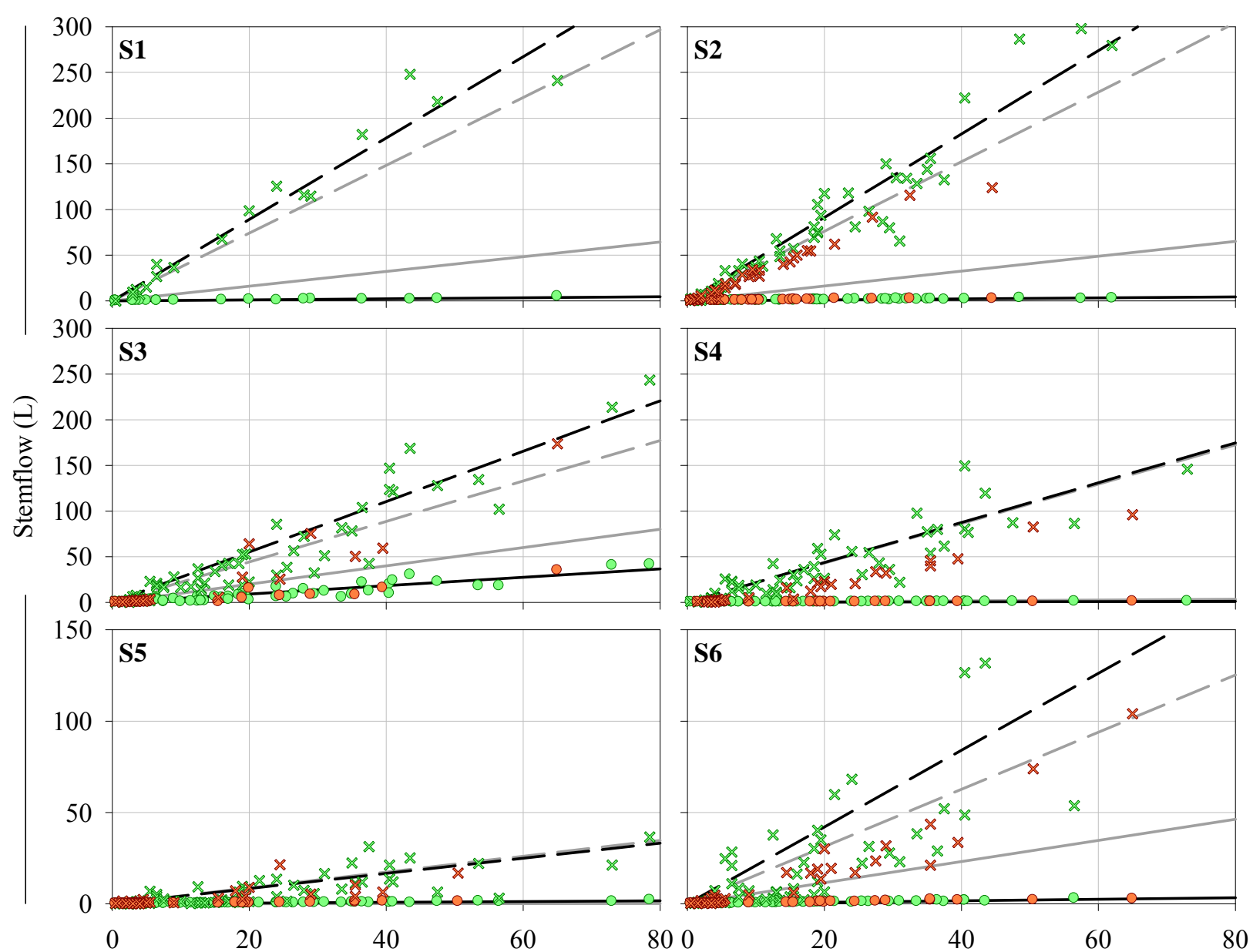

Open-area rainfall $(\mathrm{mm})$

$\begin{array}{cl}-S f_{\text {up }}^{\text {yield }} \\ -S f_{\text {down }}^{\text {yield }} & --S f_{\text {up }}^{\text {supply }}{ }_{\text {supply }} \\ -S f_{\text {down }}\end{array}$


Figure 9

Wind direction (degrees)

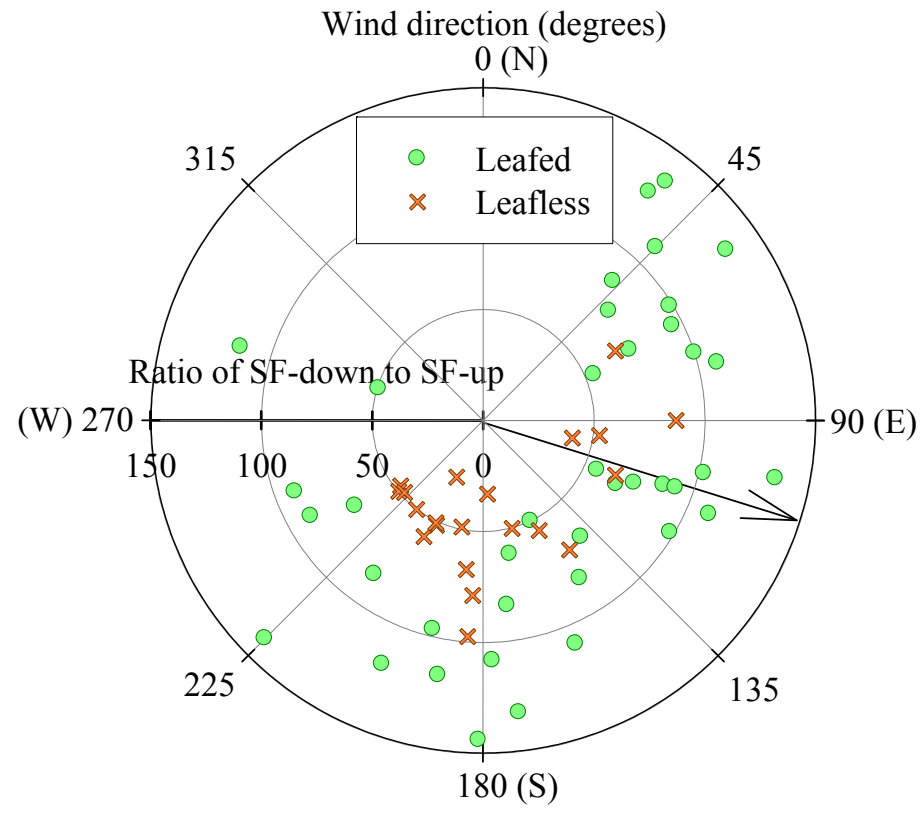


Figure 10
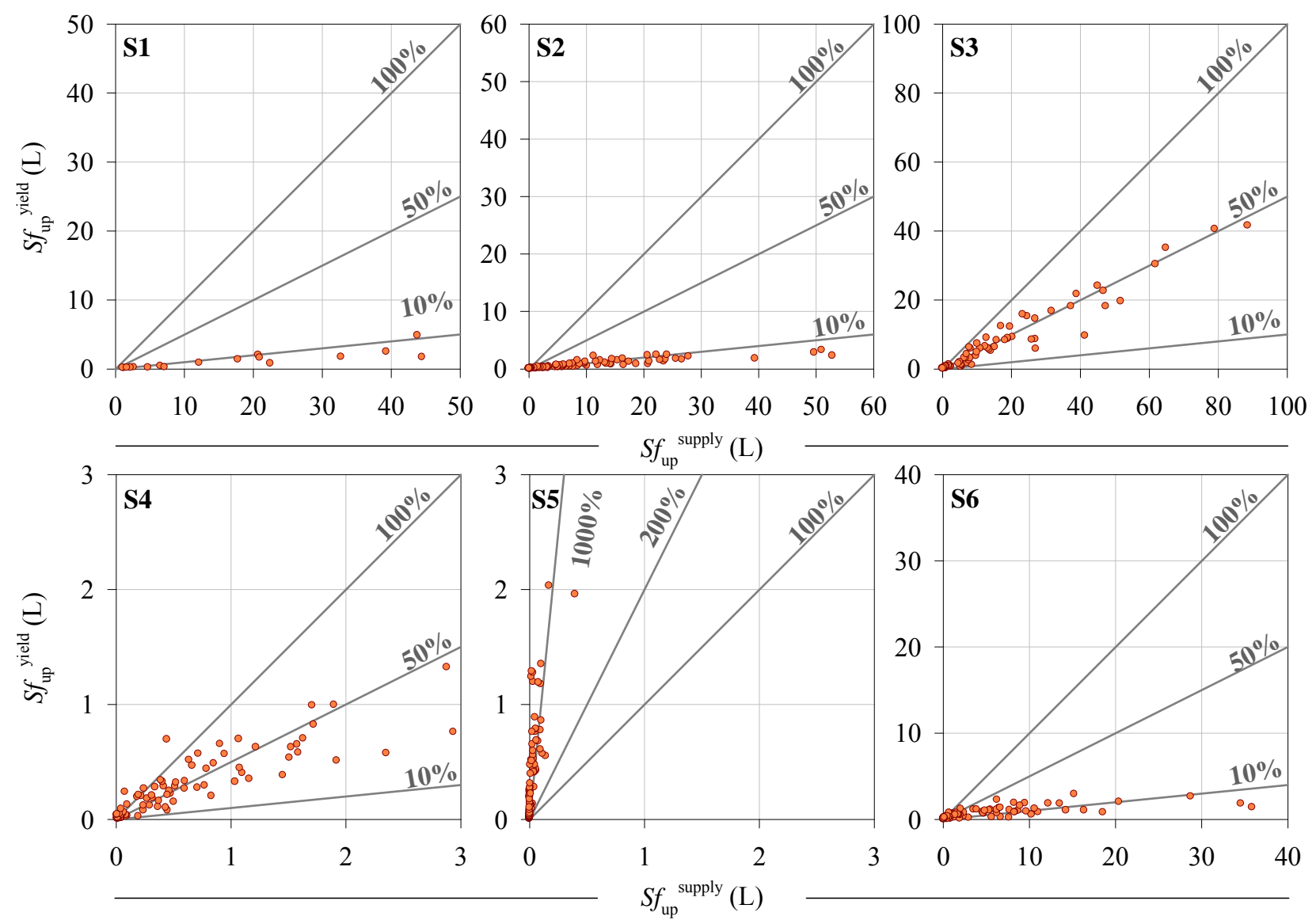
1 Table 1 Upslope, downslope, and total canopy projection area, height, diameter at breast height (DBH),

2 and angle of downslope inclination of the study tree stems.

\begin{tabular}{ccccccc}
\hline \multirow{2}{*}{ Tree } & \multicolumn{3}{c}{ Canopy area $\left(\mathrm{m}^{2}\right)$} & $\begin{array}{c}\text { Height } \\
(\mathrm{m})\end{array}$ & $\begin{array}{c}\text { DBH } \\
(\mathrm{cm})\end{array}$ & $\begin{array}{c}\text { Angle of } \\
\text { inclination }\left({ }^{\circ}\right)\end{array}$ \\
\cline { 2 - 4 } Spslope & Downslope & Total & 20.38 & 17.5 & 22.3 & 5.4 \\
S2 & 3.63 & 16.74 & 15.42 & 13.8 & 23.7 & 4.3 \\
S3 & 2.72 & 12.70 & 26.39 & 13.5 & 29.1 & 1.6 \\
S4 & 8.21 & 18.18 & 12.48 & 12.7 & 21.8 & 10.0 \\
S5 & 0.24 & 12.24 & 11.08 & 12.1 & 20.3 & 5.8 \\
S6 & 0.05 & 11.03 & 22.83 & 15.4 & 27.9 & 6.8 \\
\hline
\end{tabular}

3 
1 Table 2 The ratio of stemflow to open-area rainfall for trees S1-S6 in the leafed, leafless, and yearly 2 periods. Observation for tree S1 was only conducted in the leafed period.

\begin{tabular}{cccc}
\hline Tree & Leafed & Leafless & Yearly \\
\hline S1 & $25.9 \%$ & - & - \\
S2 & $28.1 \%$ & $19.1 \%$ & $26.0 \%$ \\
S3 & $10.9 \%$ & $7.9 \%$ & $10.3 \%$ \\
S4 & $17.2 \%$ & $8.8 \%$ & $14.7 \%$ \\
S5 & $3.4 \%$ & $2.7 \%$ & $3.3 \%$ \\
S6 & $7.6 \%$ & $4.6 \%$ & $6.6 \%$ \\
\hline
\end{tabular}

3 